\title{
Interactive comment on "Relation of aggregate stability and microbial diversity in an incubated sandy soil” by F. Büks et al.
}

\author{
F. Büks et al. \\ frederick.bueks@tu-berlin.de
}

Received and published: 24 May 2016

Relation of aggregate stability and microbial diversity in an incubated sandy soil

Frederick Büks1, Philip Rebensburg2, Peter Lentzsch2 and M. Kaupenjohann1

1 Chair of Soil Science, Department of Ecology, Technische Universität Berlin. 2 Leibniz Center for Agricultural Landscape Research (ZALF e.V.), Müncheberg, Germany

Correspondence to: F. Büks (frederick.bueks@tu-berlin.de)

Final response to \#Referee3

Dear Referee3. Thank you very much for your suggestions to improve the quality of this article. 
1) The introduction to the discussion paper focusses too greatly on biofilms, EPS composition and formation and bacterial composition with little or no discussion of aggregate stability (the aim of the paper being to relate the former to the latter). Aggregate stability is determined by both biotic and abiotic factors and this should be commented upon. In line 103 we add as follows: “... : EPS is one of manifold factors of soil aggregate stabilization. Permanent and variable charges of silicates, (hydr)oxides of Fe, $\mathrm{Al}$ and $\mathrm{Mn}$, phosphates, carbonates as well as POM interact to each other meditated by multivalent cations with small hydrate shells (e.g. $\mathrm{Ca} 2+, \mathrm{Fe} 3+$ and $\mathrm{Al} 3+$ ). Also dissolved organic matter (DOM) like humins, plant exudates and diverse decomposing products builds physico-chemical links between soil particles and covers mineral surfaces. In addition, fungal mycelia and fine roots form a stabilizing network in and around soil aggregates. (Jastrow and Miller, 1997; Bronick and Lal, 2005)". Also "However, the contribution of biofilms to this stabilization was not yet quantified." was added to line 429 .

2) The authors use sonication to disperse aggregates and then measure the release of organic carbon (OC) as a measure of aggregate stability. I am not familiar with any studies which state that aggregate stability can be measured by the quantity of OC released. The authors refer to Kaiser \& Berhe as the basis for their method, but in this paper Kaiser \& Berhe do not state their approach is a means to measure aggregate stability. Aggregate stability is typically measured by successive reduction in particle size (typically mean weight diameter) of aggregates, not by reference to the quantities of $\mathrm{OC}$ released. If it were possible to show a strong linear relationship between aggregate size and $\mathrm{OC}$ released then it might be possible to infer aggregate stability, but I do not consider the current approach in the discussion paper to be a measure of aggregate stability. The authors need to justify their approach in the context of the published literature on aggregate stability. We will include the following statement in line 420 before discussion of SOC release. "Generally, aggregate stability is characterized by determining the reduction in aggregate size after application of mechanical force. The commonly used methods are dry and wet sieving. However, the destruction of 
soil aggregates by ultrasonication has an advantage over these methods, which is the quantification of the applied energy (North, 1976). It is used for studying reduction of aggregate size (Imeson and Vis, 1984) as well as detachment of occluded POM carbon (Golchin et al., 1994). Kaiser and Berhe (2014) reviewed 15 studies using ultrasonication of soil aggregates in consideration of its destructiveness to the soil mineral matrix and occluded POM. They found destruction of POM at applied energy levels $>60 \mathrm{~J} / \mathrm{ml}$, destruction of sand-sized primary particles at $>710 \mathrm{~J} / \mathrm{ml}$ and of smaller mineral particles at higher energy levels. We used this method of gentle POM detachment from soil aggregates to measure the oLF carbon release as a result of mechanical force and linked it to aggregate stability. Since Cerli et al. (2012) showed that the release of free and occluded light fractions strongly depends on soil properties like mineralogy, POM content and composition, this method is restricted to comparison of soils differing in none of these properties."

3) The language and grammar used in the paper requires a considerable amount of revision before the paper could be accepted for publication. I have suggested several amendments in the technical corrections but there are many more than this. Thank you very much. We will do our best and consult a native speaker. 1. Correct spellings are: therefore, proteins: Done 2. use mineral, not inanimate: Done. 3. line 177; create, not receive: Done. 4. line 206; addition, not add-on: Done. 5. line 217; it is not clear what soil parallels are - please clarify: "soil samples" 6 . line 264; statistical analysis: Done. 7. line 340-341; it is not clear what is meant by "but between the two and SP pure: "... whereas both differ significantly to SPpure." 8. line 480; Our hypothesis was not supported by the data: Done.

4) I was not convinced by the evidence that biofilms are formed as a reaction to ecological stress - the citation referred does not relate to this. Please provide clear evidence/citation to this association. Flemming and Wingender (2010) only refers to "..., but also act as genetic cross-over hotspot and collective digestive system for diverse soil nutrients." References for the evidence of reaction on ecological stress are given

Interactive comment

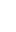


in lines 73-74 (Roberson and Firestone, 1992; Mah and O'Toole, 2001; Weitere et al., 2005; Chang et al., 2007; Ozturk and Aslim, 2010) and will be included in this paragraph in line $119 \mathrm{ff}$. to avoid misunderstanding.

5) What statistical significance can we place on results with only three replicates? A more quantitative analysis would require more replicate samples. We will add the following to the end of the discussion: "Our results give a first insight to the relation of microbial community composition, SOC release and aggregate stability. A more quantitative analysis would require more replicate samples, probably inclusion of soils from different land use and different microbial communities. However, this was beyond the scope of the present study."

6) Line 219 - 'were separated' - how were the aggregates separated? Thank you. I will delete "... separated and ..."

\section{References}

(Bronick and Lal, 2005) Bronick, Carol Jean, and Rattan Lal. "Soil structure and management: a review." Geoderma 124.1 (2005): 3-22.

(Cerli et al., 2012) Cerli, C., et al. "Separation of light and heavy organic matter fractions in soilâĂŤTesting for proper density cut-off and dispersion level." Geoderma 170 (2012): 403-416.

(Chang et al., 2007) Chang, Woo-Suk, et al. "Alginate production by Pseudomonas putida creates a hydrated microenvironment and contributes to biofilm architecture and stress tolerance under water-limiting conditions." Journal of bacteriology 189.22 (2007): 8290-8299.

(Flemming and Wingender, 2010) Flemming, Hans-Curt, and Jost Wingender. "The biofilm matrix." Nature Reviews Microbiology 8.9 (2010): 623-633.

(Golchin et al., 1994) Golchin, A., et al. "Study of free and occluded particulate organic matter in soils by solid state 13C CP/MAS NMR spectroscopy and scanning electron

SOILD

Interactive

comment
Printer-friendly version

Discussion paper 
microscopy." Soil Research 32.2 (1994): 285-309.

(Imeson and Vis, 1984) Imeson, A. C., and M. Vis. "Assessing soil aggregate stability by water-drop impact and ultrasonic dispersion." Geoderma 34.3-4 (1984): 185-200.

(Jastrow and Miller, 1997) Jastrow, J. D., and R. M. Miller. "Soil aggregate stabilization and carbon sequestration: feedbacks through organomineral associations." Soil processes and the carbon cycle (1997): 207-223.

(Kaiser and Berhe, 2014) Kaiser, Michael, and Asmeret Asefaw Berhe. "How does sonication affect the mineral and organic constituents of soil aggregates?âĂŤA review." Journal of Plant Nutrition and Soil Science 177.4 (2014): 479-495. Mah, Thien-Fah C., and George A. O'Toole. "Mechanisms of biofilm resistance to antimicrobial agents." Trends in microbiology 9.1 (2001): 34-39.

(North, 1976) North, P. F. "Towards an absolute measurement of soil structural stability using ultrasound." Journal of Soil Science 27.4 (1976): 451-459.

(Ozturk and Aslim, 2010) Ozturk, Sahlan, and Belma Aslim. "Modification of exopolysaccharide composition and production by three cyanobacterial isolates under salt stress." Environmental Science and Pollution Research 17.3 (2010): 595-602.

(Roberson et al., 1992) Roberson, Emily B., and Mary K. Firestone. "Relationship between desiccation and exopolysaccharide production in a soil Pseudomonas sp." Applied and Environmental Microbiology 58.4 (1992): 1284-1291.

(Weitere et al., 2005) Weitere, Markus, et al. "Grazing resistance of Pseudomonas aeruginosa biofilms depends on type of protective mechanism, developmental stage and protozoan feeding mode." Environmental Microbiology 7.10 (2005): 1593-1601.

Best regards, Frederick Büks

Please also note the supplement to this comment:

Discussion paper

http://www.soil-discuss.net/soil-2016-14/soil-2016-14-AC3-supplement.pdf 
Interactive comment 